\title{
PATRIMONIO CULTURAL Y EL DISEÑO: \\ EL CASO DE UN SISTEMA PRODUCTO PARA EL SITIO ARQUEOLÓGICO DE COCHASOUÍ, ECUADOR IVÁN BURBANO
}

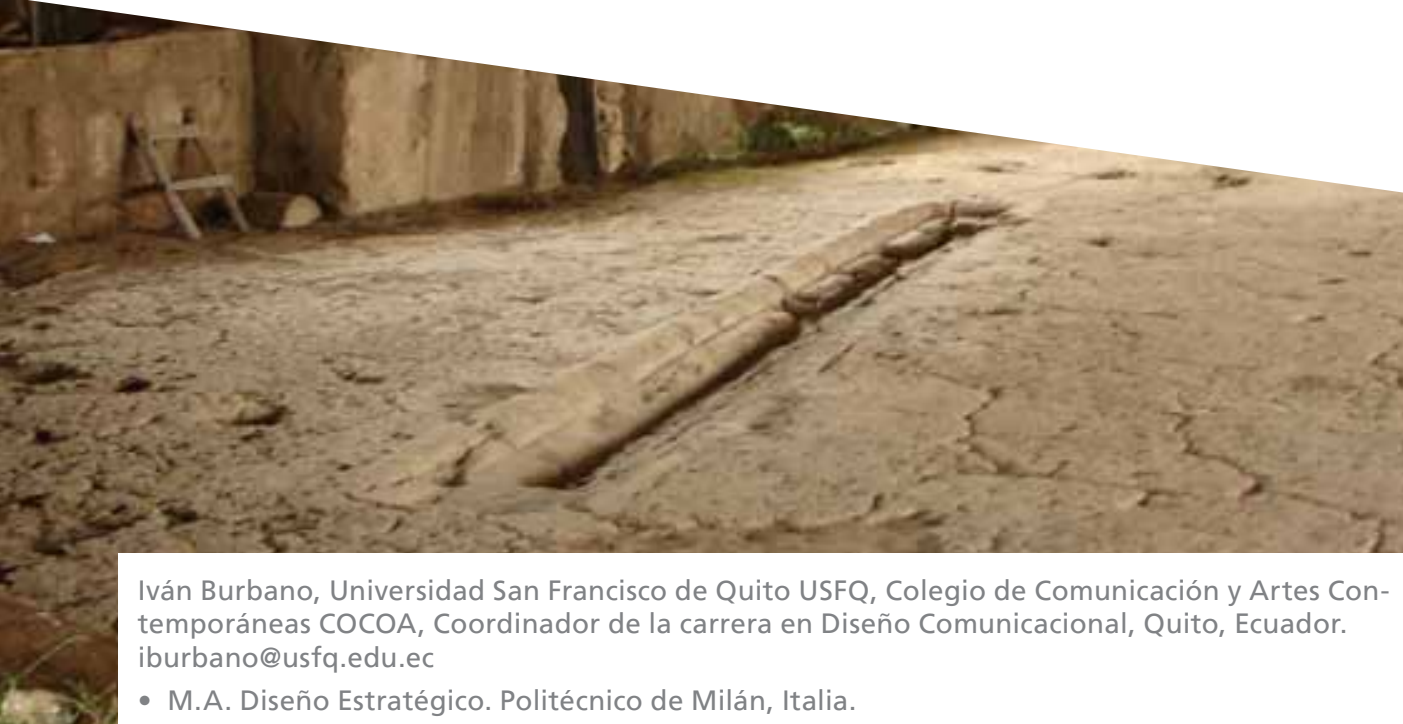




\section{Resumen}

Este ensayo resume un trabajo realizado por la Universidad San Francisco de Quito y el Connecticut College en 2010, que consistió en el desarrollo de un sistema producto sobre el sitio arqueológico de Cochasquí (Quito, Ecuador). Está constituido por un tour virtual en $3 \mathrm{D}$, modelos $3 \mathrm{D}$ de $360^{\circ}$ de las cerámicas del sitio, animaciones 3D de la relación de los solsticios y equinoccios con las pirámides del sitio, videojuegos que relatan acontecimientos históricos, recopilación de videos y fotografías del lugar, así como entrevistas, todo esto junto en un sitio web a disposición del público. La elaboración del proyecto representó un reto ante la escasez de datos y la existencia de información contradictoria. Sin embargo, la aproximación multifacética del proyecto proporciona al usuario información que le permite generar su propia interpretación del sitio.

Palabras clave: animación 3D, arqueología, Cochasquí, tecnologías de la información, reconstrucción virtual

\section{Abstract}

This essay reviews the work accomplished by Universidad San Francisco de Quito and Connecticut College that consisted in the development of a product system for the Cochasquí Archeological Site at Quito, Ecuador. This product system is composed by a 3D virtual tour, $3 \mathrm{~d}$ Models and $360^{\circ}$ visualisations of ceramics, $3 \mathrm{~d}$ animations of the solstices and equinoxes and its relationship with the pyramids of the site, video games relating historic events, video and photo compilations as well as interviews, all collected in a public web site. The lack of archeological data as well as contradictory information became a challenge for the project. However, the multifaceted approximation of the project brings the user interesting information for a creating their own interpretation.

Keywords: 3D animation, archeology, Cochasquí, information technology, virtual visualisation 


\section{Patrimonio cultural y el diseño: el caso de un sistema producto para el sitio arqueoló- gico de Cochasquí, Ecuador}

\section{Antecedentes}

El proyecto nació de la colaboración entre el Connecticut College y la Universidad San Francisco de Quito con el apoyo de la Comisión Fullbright del Ecuador a través de una beca entregada a la profesora Bridget Baird, del Connecticut College, motivadora e iniciadora del proyecto.

Las pirámides de Cochasquí se encuentran ubicadas aproximadamente $50 \mathrm{~km}$ al norte de la ciudad de Quito, Ecuador. Se estima que las pirámides datan del período comprendido entre el 500 al 1550 de nuestra era y fueron construidas por el pueblo Caranqui. El sitio arqueológico está construido a una altitud de $3.100 \mathrm{~m}$ sobre el nivel del mar sobre una colina con vista a varias montañas de la Sierra norte del Ecuador. Alrededor del año 1500, los caranquis fueron conquistados por los incas. Luego de la conquista de estos últimos 
por parte de los españoles, no es posible encontrar ningún registro sobre los caranquis a parte de ciertos relatos orales que narran sobre todo el conflicto con los incas. Hoy, el sitio es un parque arqueológico de 84 hectáreas administrado por el Gobierno de la Provincia de Pichincha.

\section{Estado actual de las pirámides}

Durante cientos de años, las pirámides permanecieron cubiertas por tierra y vegetación. Desde el nivel del piso, las pirámides parecen elevaciones naturales del terreno, por lo que durante un tiempo pasaron desapercibidas. En la época colonial, el lugar fue parte de la hacienda Cochasquí. Es de ahí de donde el sitio arqueológico toma su nombre. Durante la primera mitad del siglo XX, ladrones y vándalos dejaron al descubierto parte de una pirámide. Este suceso dio paso a que el científico alemán Max Uhle realizara excavaciones arqueológicas en el sitio durante 1939. Entre 1964 y 1965, hubo más excavaciones a cargo del equipo germano-ecuatoriano liderado por Oberem y Wuster. Pese a los estudios posteriores, la mayor parte del sitio está todavía sin explorar.

Vista posterior del sitio arqueológico.

Se puede ver la pirámide, en cuya cima

se aprecia el techo de zinc que cubre

las plataformas circulares que podrían

tratarse de observatorios astronómicos.

Burbano, I. (2010) [fotografía] 
Las excavaciones realizadas durante los años sesenta dejaron al descubierto la cima de una de las pirámides. A partir del análisis se plantearon varias hipótesis sobre su uso. La primera establece que las pirámides fueron utilizadas como vivienda y que, en la cima de estas, vivía la casta gobernante y religiosa. Otra hipótesis especula sobre un uso principalmente ceremonial. Más recientemente se ha mantenido la hipótesis de que la cima de la pirámide fue un observatorio astronómico que permitió a los caranquis desarrollar su calendario.

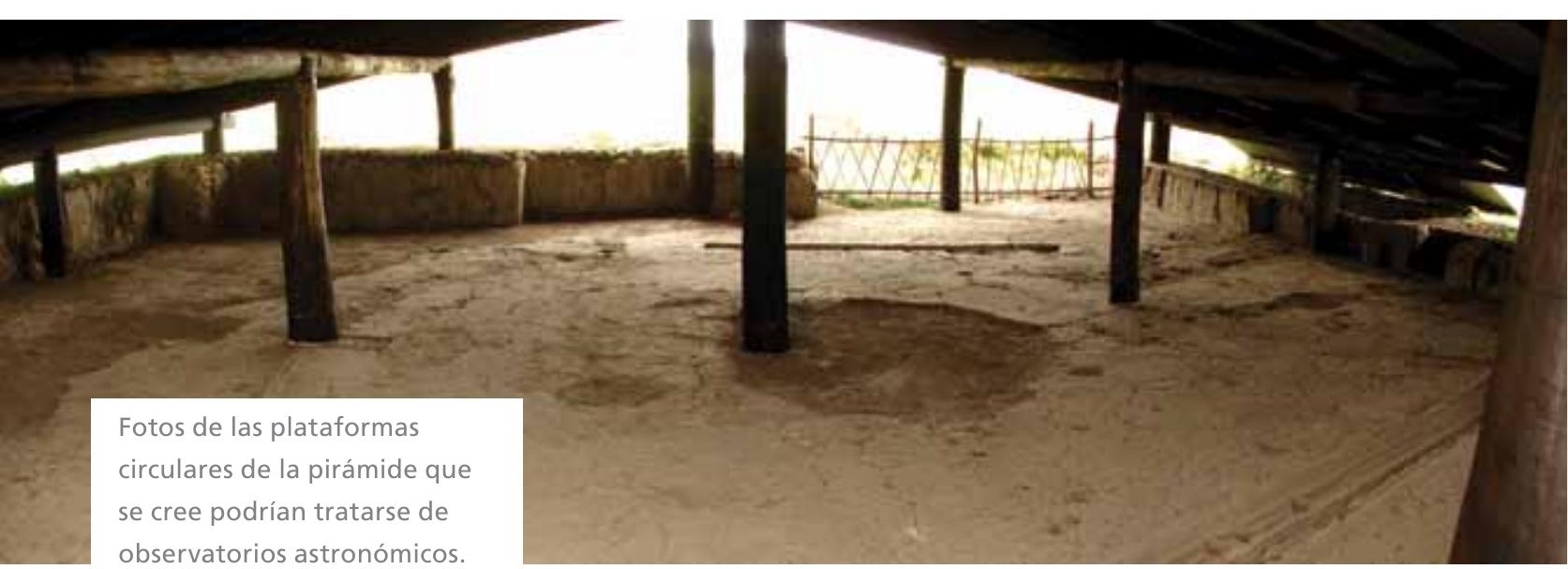

Burbano, I. (2010) [fotografías]

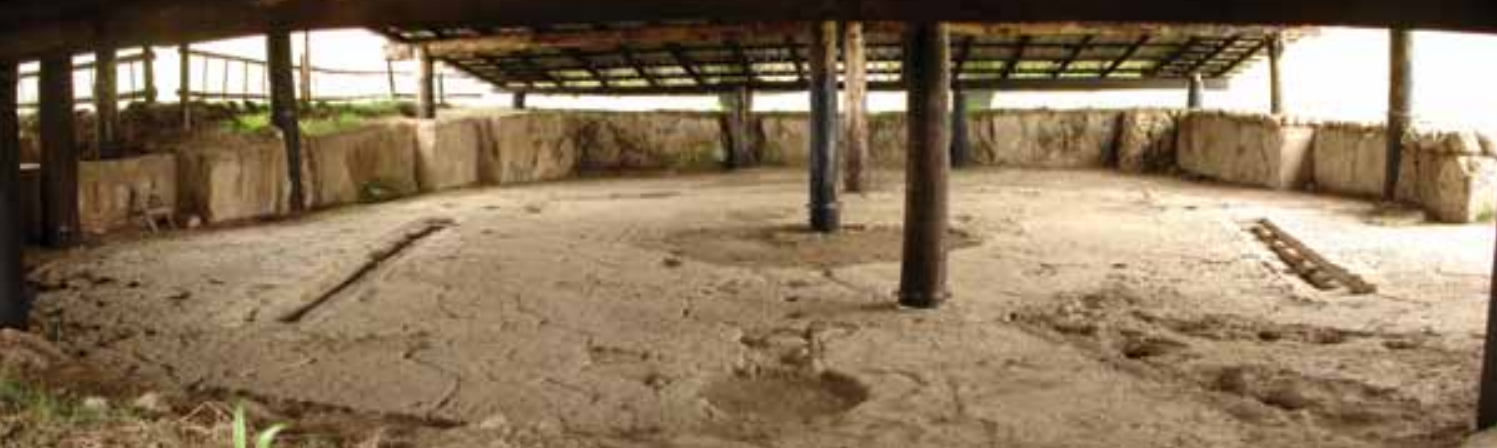


Actualmente, el sitio es un atractivo turístico que es visitado por miles de personas cada año. Existe un pequeño museo con piezas de uso cotidiano que se han recuperado del lugar. "Por el momento, no hay planes de realizar nuevas excavaciones; sin embargo, se han realizado y se están realizando algunos estudios adicionales del sitio y hay esfuerzos para expandir el museo y producir una exhibición más interactiva para los visitantes" (Baird, Okabe-Jawdat y Burbano, 2010).

\section{El proyecto}

El proyecto examina posibles estrategias para elaborar un producto de visualización de un bien cultural, en este caso el sitio arqueológico de Cochasquí, a través de un sistema producto que permita al público en general tener una experiencia virtual de una visita a las pirámides en su estado actual y en su posible estado original.

El sistema producto incluye los siguientes elementos:

1. Una visita virtual a través de un producto interactivo en 3D.

2. Modelos $3 \mathrm{D}$ de $360^{\circ}$ de las cerámicas del sitio.

3. Animaciones 3D que explican el funcionamiento del observatorio astronómico, que según la hipótesis más reciente, se encuentra en la única cima explorada de una de las pirámides.

4. Juegos para niños.

5. Fotografías, videos y audios de entrevistas.

6. Un sitio web en inglés y español que agrupa los productos enumerados anteriormente.

\section{Las TIC y su uso en la arqueología}

El uso de las tecnologías de la información es un recurso que ha adquirido un papel cada vez más relevante, 
sobre todo durante la última década. Uno de los usos más importantes es aquel relacionado a la difusión del patrimonio arqueológico al público en general a través de museos virtuales y colecciones en línea de piezas que hace poco tiempo estaban relegadas solo a quienes podían permitirse viajar hasta los lugares donde se encuentran físicamente: los museos y las colecciones.

La validez de estas reconstrucciones virtuales depende sobre todo de la fiabilidad de la información recabada. Sin embargo, hay que tomar siempre en cuenta que esta información generalmente tiene vacíos que hay que llenar con teorías y representaciones que no están corroboradas del todo. Por lo tanto, es importante una actualización periódica de la aplicación para mantenerse al día con las nuevas teorías y descubrimientos para que la información expuesta sea siempre la más precisa posible.

\section{La tecnología de visualización tridimen- sional en computador}

La tecnología que nació para disciplinas como la ingeniería y arquitectura encontró posteriormente usos relacionados al desarrollo de efectos especiales en el cine y en la publicidad. Con el avance en la capacidad de procesamiento del hardware y con la mayor accesibilidad del software, esta tecnología dejó de ser exclusiva de las instituciones y empresas y se difundió al usuario común. Esto permitió el desarrollo de aplicaciones enfocadas a mezclar la interactividad con la visualización 3D, cuyos resultados pueden verse en los videojuegos y en usos científicos como en el caso de la arqueología. En 2010, año en el cual se desarrolló nuestra aplicación, ya se contaba con software disponible para el usuario común que permitía la programación de niveles de interacción con 
modelos 3D, lo cual permitió la construcción del paseo virtual por el sitio arqueológico de Cochasquí. La aplicación se completó con el escaneo 3D de las piezas cerámicas a través de fotografías en $360^{\circ}$, que permitió una visualización tridimensional.

\section{La interacción digital en 3D en línea}

La interacción en tiempo real, que quiere decir una respuesta instantánea del modelo a las instrucciones del usuario, ha permitido la exploración y la visualización de sitios y piezas arqueológicas. En el la época en la cual desarrollamos la aplicación (2010), la difusión en línea de este tipo de productos se estaba iniciando. Uno de los pioneros fue el museo De Louvre (http://www.louvre.fr/en/visites-en-ligne). A nivel de Ecuador, la visita virtual en línea del sitio arqueológico de Cochasquí desarrollada por el Colegio de Comunicación de la Universidad San Francisco de Quito y Connecticut College fue pionera. Actualmente, este tipo de productos son ampliamente difundidos. Por ejemplo, Google, a través de su plataforma en línea, Google Cultural Institute (http://www.google.com/culturalinstitute/home), permite que cualquier persona o institución pueda elaborar su museo virtual con fotos y videos.

\section{La visita virtual}

La visita virtual se desarrolló tomando como referencia los videojuegos en primera persona. Esto quiere decir que existe un personaje principal que representa al usuario, el cual interactúa directamente con el entorno de la aplicación. Los elementos del paseo virtual son:

1. El personaje principal que está representado por una arqueóloga. 
2. El terreno que fue modelado siguiendo la topología del terreno real.

3. Las pirámides que fueron modeladas según las dimensiones tomadas durante las excavaciones de los años sesenta. Están representadas de dos formas:

a. Según el estado actual, es decir cubiertas por tierra y pasto.

b. Según el posible estado original con sus bloques de cangahua al descubierto.

El personaje camina libremente por el sitio y es controlado por el teclado. El concepto en el que se basa la aplicación es el de la exploración y el descubrimiento. El objetivo es encontrar lugares marcados distribuidos en el sitio que le permiten al usuario realizar sus propios descubrimientos. La información a la que accede el usuario está relacionada con datos históricos, hipótesis desarrolladas en las diferentes excavaciones arqueológicas, fotografías, videos y entrevistas. Durante el recorrido, el usuario puede visualizar las pirámides cubiertas por pasto, tal como se ven actualmente, o con los bloques de cangahua al descubierto, tal como pudo haber sido su aspecto originalmente. La finalidad de toda la experiencia es que el usuario tenga una base de información que le permita entender la constitución del sitio arqueológico y pueda deducir por sí mismo cómo es y cómo pudo haber sido.

Para la construcción del paseo virtual, se modelaron las pirámides, el personaje y el terreno en Autodesk MAYA que es un software de modelado y animación 3D. Estos modelos fueron producidos en diferentes niveles de resolución, lo que permite optimizar la carga en línea del paseo virtual para que pueda ser visualizado en tiempo real.

Para la animación del personaje, se usó el ciclo de la caminata y las diferentes poses. Esta información luego fue exportada en formatos de archivos digitales para su 
Captura de pantalla que muestra el plano general del complejo y, en el círculo, la ubicación del usuario respecto a este.

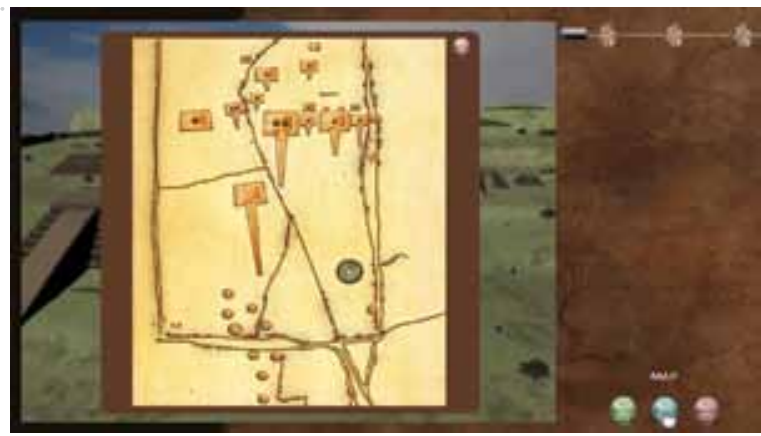

Secuencia de tres imágenes de la aplicación que muestran al complejo cubierto, tal como es actualmente y las dos hipótesis de cómo pudo verse originalmente: La estructura de cangahua enlucida de barro y la estructura de canhagua al

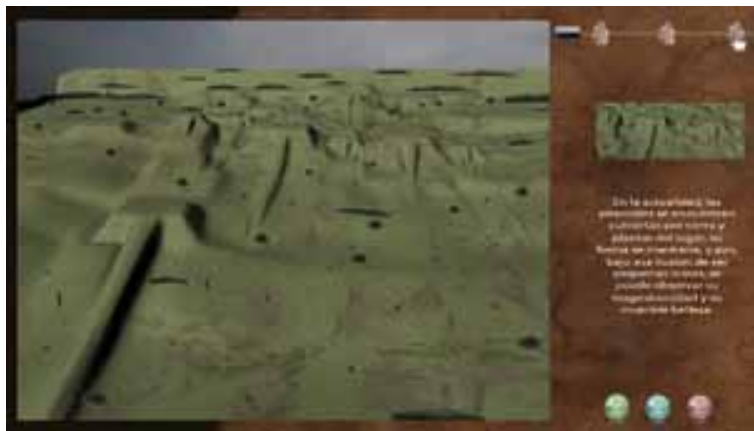
descubierto.

Baird, B. Burbano, I. Escobar, D. Yánez, A. Páez, E. Okabe-Jawdat, E. (2010) [visita virtual]
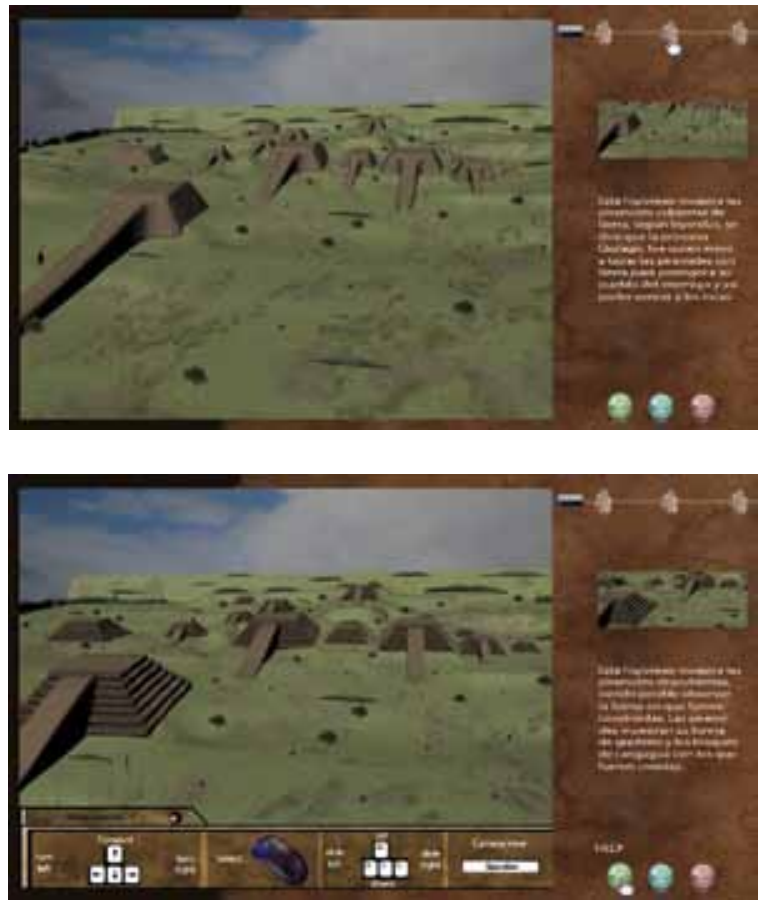
Imágenes en donde se puede ver la interacción del usuario con el complejo virtual a través del personaje en $3 \mathrm{D}$ que representa a una arqueóloga.

Baird, B. Burbano, I. Escobar, D. Yánez, A. Páez, E. OkabeJawdat, E. (2010) [visita virtual]
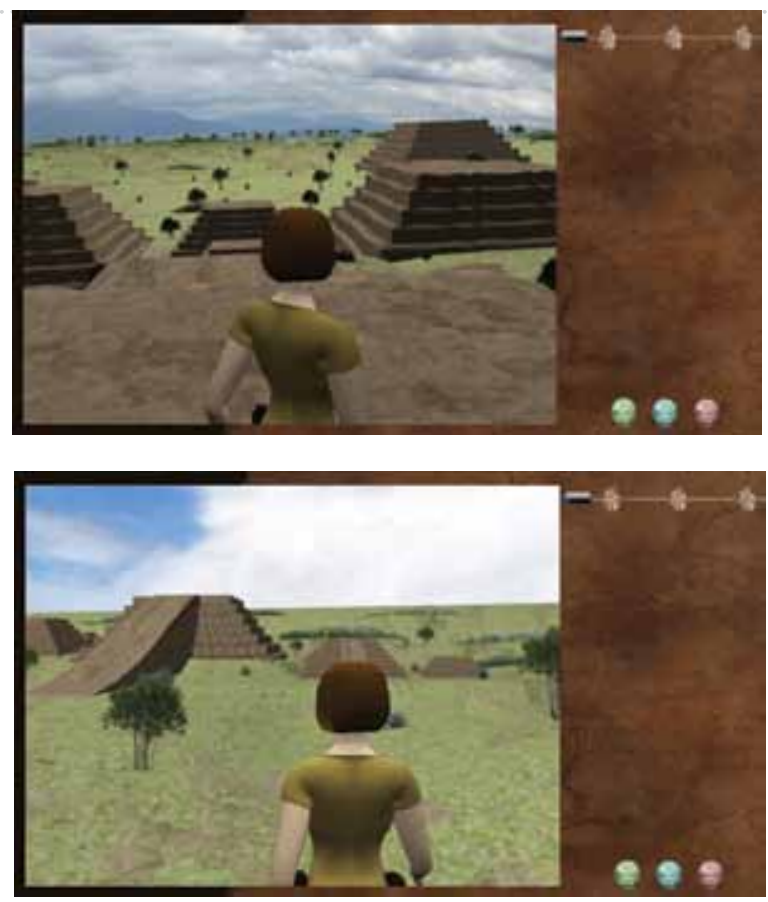

posterior uso en otras aplicaciones que permitan desarrollar la interactividad con el usuario.

Posteriormente, los modelos 3D fueron importados en un programador de niveles, en este caso específico fue Dassault Systems Virtools. Este software permite programar los diferentes niveles de interactividad de los modelos, los ciclos animados, las poses del personaje y la información del sitio para que el usuario, utilizando el teclado de su computador, pueda realizar el paseo virtual. La aplicación luego fue exportada en un formato que permite su carga en línea a través de un Plug In de Vortools que debe ser cargado previamente en el navegador.

\section{Modelos digitales 3D de las cerámicas del sitio}

Se realizaron también representaciones tridimensionales de las cerámicas encontradas en el sitio arqueológico 
que están expuestas en el museo de sitio. Gracias al apoyo del Gobierno Provincial de Pichincha, se pudo acceder a las piezas con el fin de realizar sesiones fotográficas de $360^{\circ}$ que permitieron posteriormente digitalizarlas en tres dimensiones.

El objetivo de estos modelos digitales es que el usuario pueda visualizar las cerámicas en $360^{\circ}$ a través de su computador. Los modelos fueron construidos utilizando una serie de fotografías de $360^{\circ}$ de cada pieza cerámica. Estas fotos luego son cargadas en Strata 3D (www.strata.com) que es capaz de unir las imágenes para convertirlas en un modelo 3D que luego puede ser exportado en formato SWF (FlashPlayer) para ser visualizado en $360^{\circ}$ en línea.

\section{Animaciones sobre el uso del observatorio astronómico}

Otro producto son las animaciones que representan los solsticios y los equinoccios y su relación con el observatorio astronómico en la cima de la pirámide E del complejo. En las animaciones, se puede apreciar la relación entre la sombra producida por un cilindro que se cree que fue parte del observatorio, y los canales a los lados que poseen marcas que indican la posición de la sombra según la época del año. Esto les permitía a los caranquis planificar las épocas de siembra y cosecha durante su calendario.

\section{Juegos para niños}

Los juegos fueron pensados para proporcionar a los niños una forma entretenida de aprender sobre las pirámides y su historia. Se desarrollaron dos juegos en Adobe Flash: 1. Un rompecabezas con tres niveles de dificultad. El objetivo es armar, en un tiempo determinado, las 
Capturas de pantalla de las animaciones que muestran a las plataformas circulares de la pirámide E y su posible uso como observatorios astronómicos. En la imagen superior la interacción del sol durante el solsticio de junio con una columna que se supone estaba en el centro de la plataforma.

\section{Burbano, I. Escobar, D.}

Yánez, A. Páez, E. (2010)

[modelación y animación 3D]
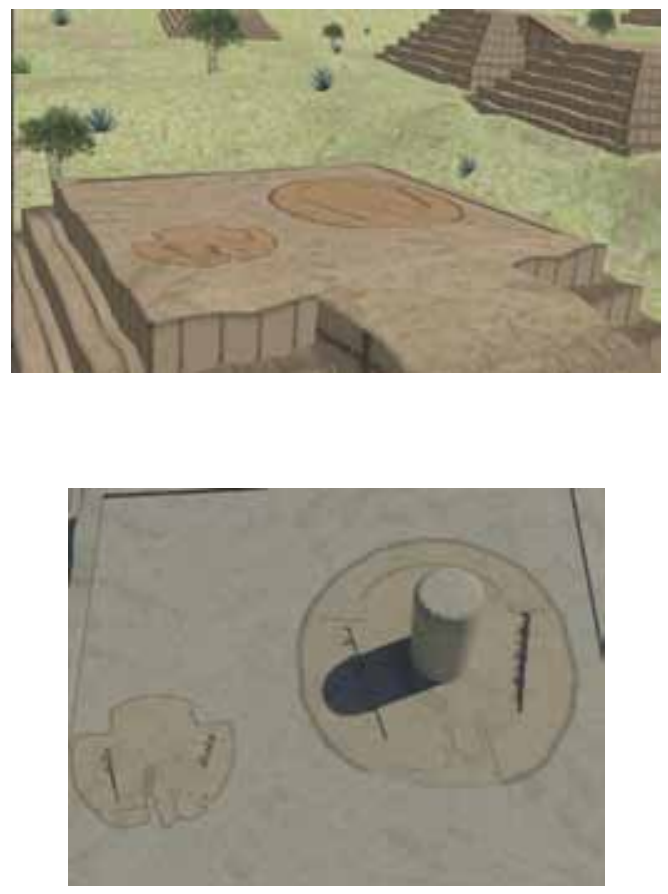

piezas que componen imágenes de las cerámicas de Cochasquí.

2. Un juego que representa la batalla entre los caranquis y los incas. Cuenta la leyenda que la cacique Quilago se enfrentó valientemente junto a su ejército a los incas. Pese a su tenacidad, los caranquis fueron vencidos tras ofrecer resistencia en la laguna que actualmente se llama Yaguarcocha que en kichwa quiere decir Laguna de Sangre.

\section{Fotografías, videos y entrevistas}

Durante la investigación, se realizaron un conjunto de fotografías del sitio y de las cerámicas y diversos objetos encontrados en el lugar. Estas fotografías permiten 
apreciar las pirámides en la actualidad y sobretodo lo que se cree fue un observatorio astronómico en la cima de la pirámide También se recolectaron fotos históricas de las excavaciones realizadas durante los años sesenta que pertenecen a la colección del Parque Arqueológico de Cochasquí y al Gobierno de la Provincia de Pichincha.

Se realizaron también videos del sitio y entrevistas. Estas últimas permiten conocer las diferentes opiniones tanto de un habitante de la zona, del director del Parque Arqueológico y de uno de los guías respecto a las pirámides y su historia.

\section{El sitio web}

El sitio web fue desarrollado con la idea de aglutinar toda la información y hacerla accesible al público en general. El sitio web contiene la siguiente información:

1. El tour virtual en $3 \mathrm{D}$

2. Historia

3. Media

a. Fotos actuales

b. Fotos históricas

c. Entrevistas

d. Cerámicas en 3D

e. Videos

4. Juegos

5. Créditos

6. Documentación

El sitio web está disponible en inglés y español en el URL www.cochasquí.org

Dado que el nivel de confiabilidad de la información varía dependiendo de las fuentes, se han establecido tres escalas de confiabilidad: verde (muy confiable), amarillo (abarca algo de hipótesis), rojo (la información es poco 

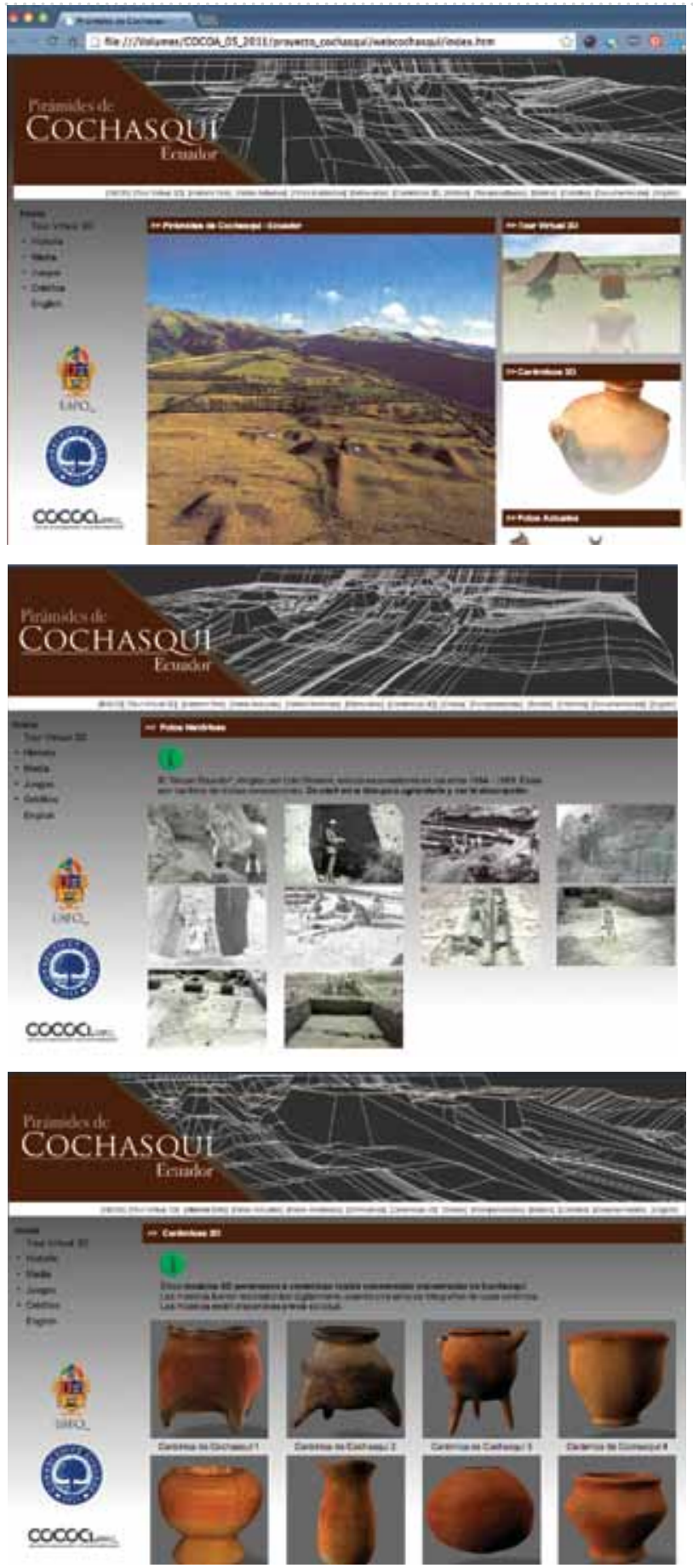
confiable y puede caer en la categoría de leyenda). Cuando el usuario da clic en los íconos, puede obtener información sobre las fuentes. El sitio web fue desarrollado utilizando Adobe Dreamweaver y Adobe Flash.

\section{Conclusión}

Para la recreación virtual de un lugar, fue importante la selección del sitio adecuado. Cochasquí fue ideal, ya que es un lugar monumental con una rica historia y tradición. Es además un sitio donde se puede analizar la relación que tenían los antiguos habitantes de lo que hoy conocemos como Ecuador con las montañas de los Andes. El probable uso de las pirámides como observatorios astronómicos nos dice mucho sobre el nivel de complejidad de los Caranquis. Estas características demuestran que la selección del sitio arqueológico de Cochasquí dan como resultado un lugar con un potencial narrativo amplio.

El enfoque multifacético permite una interacción más amplia con el usuario, y le permite interpretar de manera más clara la información. El uso del paseo virtual y de las representaciones 3D de las cerámicas permiten al usuario considerar las diferentes hipótesis e interpretaciones planteadas sobre el uso que se les daba a las pirámides. Finalmente, esto permite tener una mejor comprensión del sitio y la complejidad de su exploración arqueológica. post(s).

\section{Referencias}

ATHENS, J.

1979 El proceso evolutivo en las sociedades complejas y la ocupación del período Tardo-Cara en Los Andes Septentrionales del Ecuador. Colección Pendoneros. Otavalo: Instituto Otavaleño de Antropología. 
MARTENS, B., HERBERT, P.

2010 "Displacing the Frontiers of Reconstructed Cultural Heritage". En B. Dave, A. I. Li, N. Gu, H.-J. Park (editores). New Frontiers: Proceedings of the 15th International Conference on Computer-Aided Architectural Design Research in Asia CAADRIA 2010: 63-72.

CASA DE LA CULTURA ECUATORIANA

1978 La arqueología en la Región Interandina de Ecuador. Quito: Casa de la Cultura Ecuatoriana.

COSTALES, $\mathrm{P}$.

1991 Historia India de Cochasquí. Quito: H. Consejo Provincial de Pichincha.

HOLGUÍN, A.

2010 "El sistema calendárico y ritual de las pirámides de Cochasquí". Artículo en vías de publicación en el libro de la Sociedad de Amigos de la Genealogía e Historia, capítulo Sierra Norte. Quito.

LUMBRERAS, L.

1990 Cronología Arqueológica de Cochasquí. Quito: H. Consejo Provincial de Pichincha.

MOSCOSO, L. y COSTA, G.

1989 Historia Oral de Cochasquí. Quito: H. Consejo Provincial de Pichincha.

OBEREM, U.

1981a Cochasquí: estudios arqueológicos. Colección Pendoneros. Otavalo: Instituto Otavaleño de Antropología.

1981b Los Caranquis de la Sierra Norte del Ecuador y su Incorporación Tahuantinsuyu. Contribución a la Etnohistoria Ecuatoriana. Colección Pendoneros. Otavalo: Instituto Otavaleño de Antropología.

1975 "Informe de trabajo sobre las Excavaciones de 1964/1965 en Cochasquí, Ecuador," Estudios sobre la Arqueología del Ecuador, BAS 3, Bonner, Amerikanistische Studien, Bonn (1975). 
1970 "Montículos funerarios con pozo en Cochasquí". En Boletín de la Academia Nacional de Historia 53. Quito. No. 116: 243-249.

OBEREM, U. y WURSTER, W.

1989 Excavaciones en Cochasquí. Ecuador: Verlag Philipp Von Zabern, Mainz am Rhein.

ORTÍZZ ARCINIEGAS, L.

2009 Cochasquí. El agua del frente de la mitad. Quito: Fondo Editorial Letras.

QUINTEROS, R.

1982 Informe preliminar sobre aspectos morfológicos de los monumentos y vestigios arqueológicos de Cochasquí en Ecuador. Quito: Programa Cochasquí, Consejo Provincial de Pichincha.

RODRÍGUEZ, J.

1983 Historia de Cochasquí. Quito: H. Consejo Provincial de Pichincha.

UHLE, M.

1939 "Las Ruinas de Cochasquí". En Boletín de la Academia Nacional de Historia 18. Quito. No. 54: 5-14.

YUREVICH, V., REYES, A. ESPÍN, L. y GUAYASAMÍN, G.

1995 “Orientación Astronómica de algunos Monumentos Arqueológicos del Ecuador". Revista Geográfica 35. Instituto Geográfico Milita. Quito: 185-206.

ZIOLKOWSKI, M. y SADOWSKI, R.

1992 La arqueoastronomía en la investigación de las culturas andinas. Colección Pendoneros. Otavalo: Instituto Otavaleño de Antropología y Banco Central del Ecuador. 